\title{
TO STUDY THE CORRELATION BETWEEN PLACENTAL THICKNESS AND AMNIOTIC FLUID INDEX IN THIRD TRIMESTER OF UNCOMPLICATED PREGNANCY IN INDIAN FEMALES
}

\author{
Mumal Nagwani ${ }^{\star}$, P.K. Sharma*, Anita Rani ${ }^{\star \star}$, Urmila Singh ${ }^{\star \star}$, Seema Mehrotra** \\ *Department of Anatomy, Era's Lucknow Medical College \& Hospital, Lucknow, UP \\ ${ }^{* *}$ Department of Obstetrics \& Gynaecology, King George’s Medical University, Lucknow, UP
}

\begin{abstract}
Introduction: Placenta is the most important temporary organ during pregnancy. Healthy placenta is utmost needed for a healthy baby. Ultrasonography is the preferred modality for antenatal evaluation of placenta. Amniotic fluid plays a major role in fetal growth and development and for adequate amniotic fluid volume, a normally developed placenta is required. Thus, Placental parameters may indirectly affect the amniotic fluid volume which plays a crucial role for fetal development.
\end{abstract}

Material \& Methods: One hundred (100) antenatal cases were recruited for the present study. Those women who were with uncomplicated, singleton pregnancy of more than 26 weeks and gave their written informed consent, were taken as subjects. Thickness of the placenta was measured at the level of cord insertion. Amniotic Fluid Index (AFI) was obtained by adding the vertical lengths of deepest fluid pockets in four uterine quadrants.

Results: The mean placental thickness in third trimester was found as $3.90 \pm 1.1 \mathrm{~cm}$ and mean AFI as $125.20 \pm 38.5$.

Conclusion: A linear but inverse correlation was observed between placental thickness and amniotic fluid index.

Keywords: Placenta, placental thickness, amniotic fluid.

\section{INTRODUCTION}

During pregnancy, the most important temporary organ is placenta. It is formed during pregnancy in the lining of the uterus. It is an organ fundamentally of fetal origin. When fully formed it has an average diameter of $15 \mathrm{~cm}$ and thickness of about $3 \mathrm{~cm}$. The primary function of placenta is to permit substances dissolved in the blood of mother to diffuse into the blood of fetus and vice versa [1]. Thus, this has been emphasized that normal development of placenta is crucial for normal growth of the fetus, however, still the placenta is one of the least understood and most understudied organ in the human body. For centuries, while the anatomy of other organs has been studied in detail by ultrasonography, the placenta has often been ignored.

Amniotic fluid plays a major role in fetal growth and development. Initially, some amniotic fluid is secreted by amniotic cells; most is derived from maternal tissue and interstitial fluid by diffusion across the amniochorionic membrane from the decidua parietalis. Later, there is diffusion of fluid through the chorionic plate from blood in the intervillous space of the placenta. The volume of amniotic fluid normally increases slowly, reaching approximately $30 \mathrm{ml}$ at 10 weeks, $350 \mathrm{ml}$ at 20 weeks, and 700 to $1000 \mathrm{ml}$ by 37weeks [2].

Therefore, for adequate amniotic fluid volume, a normally developed placenta is required. Thus, placental parameters may indirectly affect the amniotic fluid volume which plays a crucial role for fetal development.

Ultrasonography is the modality of choice for antenatal evaluation of placenta as well as exact determination of amniotic fluid. Thus, this study is

Address for Correspondence:

Dr Mumal Nagwani, Associate Professor, Department of Anatomy, Era's Lucknow Medical College \& Hospital, Sarfarazganj, Hardoi Road, Lucknow-226003, UP, India. Mob: 9415795821 Email: mumalnagwani@yahoo.in 
meant for providing a baseline data of placental thickness and placental volume and their effect on amniotic fluid index in third trimester of normal pregnancy.

\section{MATERIALS AND METHODS}

This study was conducted in the Department of Anatomy, King George's Medical University, Lucknow in collaboration with Department of Obstetrics and Gynaecology, Queen Mary's Hospital, King George's Medical University, Lucknow. One hundred (100) antenatal cases were recruited for the present study. Recruited patients were divided into four groups according to gestational age (Table 1). Those women who were with uncomplicated, singleton pregnancy of more than 26 weeks and gave their written informed consent, were taken as subjects. All cases of fetal congenital anomaly, Placental anomaly, maternal medical diseases, maternal gynecological diseases and maternal obstetrical diseases which can cause oligohydramnios or polyhydramnios were excluded from the study. The gestational age was confirmed by previous ultrasonography reports of first trimester. All ultrasound examinations were performed on model $\mathrm{LOGIQ}^{\mathrm{TM}}$ a 200 ultrasound machine and on L\&T Medical, Sonata (version 3.1) machine, with a curvilinear $3.5-\mathrm{MHz}$ transducer. The placenta was identified as a hyper-echoic area separated from fetus by a hypo-echoic area of amniotic fluid.

\section{Thickness (T) of Placenta}

The probe was moved all over the localized placenta and the level of cord insertion was identified over the fetal surface. A straight line was drawn from the level of cord insertion up to the maternal surface of the placenta and thus thickness was measured [3] (Fig.1).

\section{Amniotic Fluid Index (AFI)}

AFI was obtained by adding the vertical lengths of deepest fluid pockets in four uterine quadrants. Those pockets were considered for AFI in which no fetal part or cord were seen. Fetus was also seen for the presence of any major congenital anomaly [3] (Fig. 2).

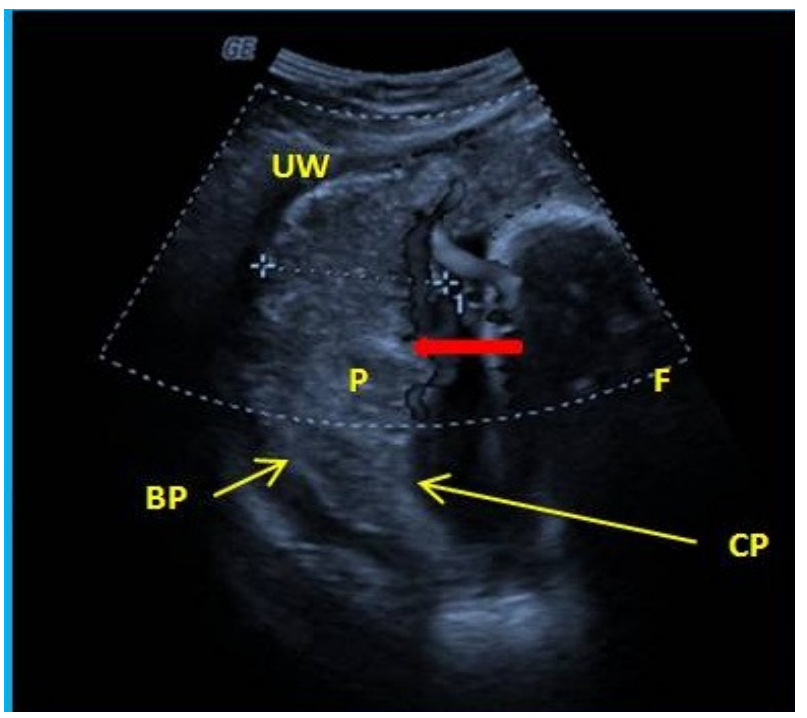

Fig 1: Measurement of placental thickness in USG

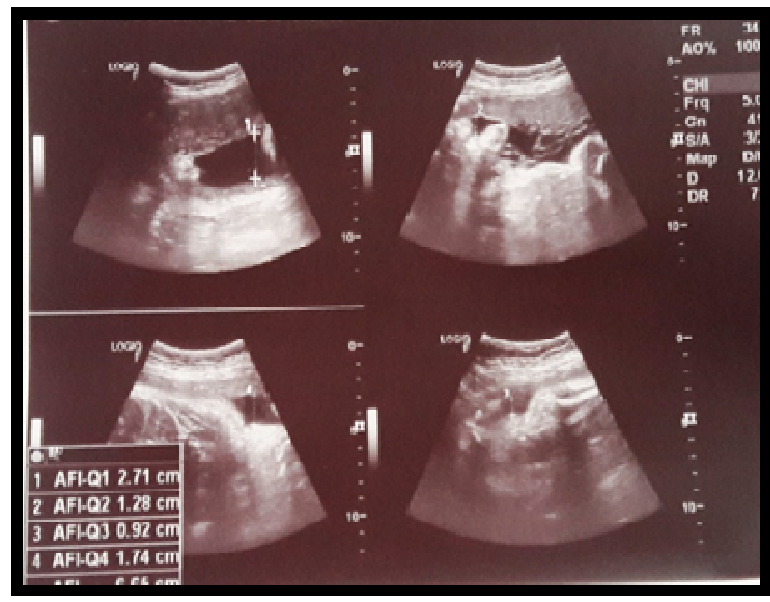

Fig 2: Measurement of Amniotic fluid index in USG

Ultrasound images were recorded and stored. Data were transferred on an excel sheet. Data were analyzed using statistical software package, STATA 11.2 and the difference was considered to be significant if ' $p$ ' value was found to be $<0.05$.

\section{OBSERVATIONS AND RESULTS}

The mean placental thickness in third trimester was found as $3.90 \pm 1.1 \mathrm{~cm}$ and mean $\mathrm{AFI}$ as $125.20 \pm 38.5$. It was observed that as the placental thickness increases with gestational age, the volume of amniotic fluid decreases. However, in the last gestational group, 
Placental thickness and amniotic fluid index......

i.e., $38^{+}-42$ weeks, the mean of placental thickness as well as amniotic fluid index both were observed to be decreased (Table 1).

Table 1: Correlation of placental thickness $(T)$ with Amniotic fluid index (AFI)

\begin{tabular}{|l|c|c|}
\hline $\begin{array}{l}\text { Gestational } \\
\text { age }(\mathbf{w k s})\end{array}$ & $\begin{array}{c}\text { Thickness } \\
(\mathbf{c m}) \\
\text { Mean } \pm \text { S.D. }\end{array}$ & $\begin{array}{c}\text { Amniotic fluid } \\
\text { index }(\mathbf{m m}) \\
\text { Mean } \pm \text { S.D. }\end{array}$ \\
\hline $26-30(n=21)$ & $3.56 \pm 0.8$ & $144.50 \pm 45.5$ \\
\hline $30^{+}-34(n=26)$ & $4.01 \pm 1.2$ & $134.18 \pm 32.0$ \\
\hline $34^{+}-38(n=41)$ & $4.05 \pm 1.3$ & $119.52 \pm 35.5$ \\
\hline $38^{+}-42(n=12)$ & $3.73 \pm 0.8$ & $91.41 \pm 19.7$ \\
\hline Total $(n=100)$ & $3.90 \pm 1.1$ & $125.20 \pm 38.5$ \\
\hline
\end{tabular}

( $n=$ number of patients, $A F I=125.5-.07^{\star} P T, p=0.983$ )

On applying regression analysis, it was observed that there is a linear correlation between placental thickness and amniotic fluid index. The analysis yielded following equation:

$$
\mathrm{AFI}=125.5-0.7^{*} \mathrm{PT}
$$

Where AFI is amniotic fluid index, PT is placental thickness. According to above equation, if placental thickness increases by one unit, amniotic fluid index decreases by 0.7 units. The p-value was $>0.05$, therefore the correlation was not significant.

\section{DISCUSSION}

Normally the placental morphology varies considerably during its short life span. Alterations in placenta as part of "Ageing" phenomenon are probably a part of maturation process and go hand in hand with continued growth of placenta. Placenta grows till 37th week and as a result immature villi are seen even till term [4]. Hence, in the study on placenta, Fox (1975), has stressed the importance of analyzing the placental pathology quantitatively and has stated that the importance of the lesions could be realized only when assessed in relation of fetal growth and maturation [5]. The thickness of the placenta may give indirect information on the foeto-placental ratio. It may give an indication of the amount of substances (nutrients, gases) that is exchanged between the foetus and the mother. Thin placenta may be due to intrauterine growth retardation, placental infarction and pregnancy with essential hypertension and pre-eclampsia [6].
In this study, we observed that the thickness of placenta increases as the pregnancy advances. However, beyond a certain limit (38 weeks in our study), the mean placental thickness starts decreasing though the placental growth is still occurring by increasing the surface area. It was suggested that raised amniotic pressure in hydramnios compressed the placenta and intervillous space [7, 8]. However, to what extent this reason could be applied for explanation of decrease in placental thickness even after decrease in AFI in normal pregnancies is to be investigated. Thus, a further research and investigation is needed on a large population to answer the above queries.

Gupta et al. (2018) studied association of placental thickness and amniotic fluid volume in cases of oligohydramnios and observed a non-significant correlation between the two parameters [9].

Akgunduz et al. (2014) evaluated the correlation between placental thickness and amniotic fluid index in cases of normal pregnancies and in polyhydramnios. They observed that the placental thickness was significantly lower in the patients with polyhydramnios compared to the patients in the control group and suggested a possible inverse ratio between the two [10]. Similar observations were made in our study, i.e., an increase in placental thickness will lead to decrease in $\mathrm{AFI}$.

\section{CONCLUSION}

In normal pregnancies, though there is a correlation between placental thickness and AFI, but it is not a statistically significant one. Statistically significant decrease in placental thickness with increase in AFI can occur only when AFI crosses a certain limit as in hydramnios.

\section{REFERENCES}

1. Hasan M, Singh D. The female reproductive system. In: Diagnostic Histology. Bharti Publisher. Anita Prakashan. 1974; 309-340.

2. Moore K and Persaud TVN. The placenta and membranes. In: The Developing Human. Saunders Publisher, Elsevier: 2015; 110-143.

3. Rumack CM and Levine D. Sonographic evaluation of the placenta. In: Diagnostic Ultrasound. Philadelphia PA. Elsevier Science publications. 2018; 1465-1358.

4. Appiah PK. Relationship between the morphology of the placenta, umbilical cord and perinatal outcome. 2009; Available from knust.edu.gh. 
5. Fox $\mathrm{H}$. The morphological basis of placental insufficiency. The Journal of Obstetrics and Gynaecology of India. 1975; 25: 441450 .

6. Habib FA. Prediction of low birth weight infants from ultrasound measurement of placental diameter and thickness. Annals of Saudi Medicine. 2002; 22 (5-6): 312-314.

7. Bower SJ, Flack NJ, Sepulveda W, Talbert DG, Fisk NM. Uterine artery blood flow response to correction of amniotic fluid volume. Am J Obstet Gynecol. 1995; 173 (2): 502-507.
8. Fisk NM, Vaughan J, Talbert D. Impaired fetal blood gas status in polyhydramnios and its relation to raised amniotic pressure. Fetal Diagn Ther. 1994; 9: 7-13.

9. Gupta A, Musharaf S, Singh G, Gupta A. Morphological changes in placenta in cases of oligohydramnios. Int $\mathrm{J}$ Reprod Contracept Obstet Gynecol. 2018; 7(4): 1518-1522.

10. Akgunduz E, Erkilinc S, Tokmak A, Guzel A I, Ozer I, Danisman N. Decreased placental thickness and impaired Doppler indices in idiopathic polyhydramnios: a prospective case-control study. J Matern Fetal Neonatal Med. 2015; 28 (6):722-725. 